\title{
The continuing evolution of targeted therapy for inflammatory skin disease
}

\author{
C. Schlapbach ${ }^{1}$ A. A. Navarini ${ }^{2}$
}

Received: 23 August 2015 / Accepted: 25 August 2015 / Published online: 30 September 2015

(C) Springer-Verlag Berlin Heidelberg 2015

\begin{abstract}
Treatment of inflammatory skin disease has evolved from non-specific suppression of immune cells to increasingly precise targeting and modulation of immune mechanisms at all levels. This has led to dramatic treatment successes and deepened understanding of the pathophysiology. The cycle of in vitro studies, animal models, clinical trials, and case series of non-primary indications is a feedback loop that informs and guides the design of ever better disease models and therapeutic targets. Not only are we constantly discovering new molecules driving skin inflammation, we have also found that psoriasis and other autoimmune conditions are driven by distinct mediators occurring in early and late phases, which could be an opportunity for phase-specific or multipronged interventions. The deeper our mechanistic understanding, the more likely we will be able to discover subtle strategies to reprogram each patients' immune cells without having to dampen or eliminate their protective effects against pathogens and tumors. Lastly, ongoing genomic studies might soon confirm interesting genetic markers for predictive personalized medicine, the earliest currently being evaluated in psoriasis such as HLA-Cw6 and TNFAIP3. Taken together, the continued evolution of immune therapies in skin will potentially allow an unprecedented form of medicine that is not bent on silencing the pathogenic mechanism, but rather
\end{abstract}

This article is a contribution to the Special Issue on Immunodermatology - Guest Editors: Lars French and Alexander Navarini

\section{A. A. Navarini}

alexander.navarini@usz.ch

1 Department of Dermatology, University of Bern, Bern, Switzerland

2 Department of Dermatology, University Hospital of Zurich, Zurich, Switzerland aims at using subtle interventions to shepherd the immune cell swarm back on the correct path.

Keywords Biologics · Inflammation · Swarm · Combined · Phase-specific

\section{Introduction}

Thanks to novel insights into the genetic and immunological background of inflammatory skin disease, we have today a better understanding of the complex molecular and cellular events that initiate and maintain inflammation in cutaneous pathology. Increasingly realistic concepts of the pathogenesis have driven the development of targeted therapies with unprecedented clinical efficacy. In turn, feedback from translational and clinical studies of patients treated with targeted therapies is continuously utilized to guide the refinement and validation of these disease concepts (Fig. 1) [1].

Good examples for this mechanism are the discovery of the role of TNF- $\alpha$ in psoriasis by initial chance observations and subsequent clinical trials, which improved our understanding of psoriasis models enormously.

In this article, we will first discuss the growing family of targeted therapies under the viewpoint of emerging models of inflammatory skin disease, namely the dichotomous models of triggering vs. maintenance and suppression vs. deviation of immune responses, and evaluate conclusions that can be drawn from observing clinical outcomes in patients under this view. We will revisit the question whether immunopathology is formed by a single long-lasting period of immune cell activation, or a series of short-lived activation triggers, or rather a combination of both. Subsequently, the review addresses whether we should strive to silence unwanted immune cells or rather try to reprogram them. Then, we will evaluate the 
Fig. 1 The cycle of induction and deduction: from pathogenesis to targeted therapies and back

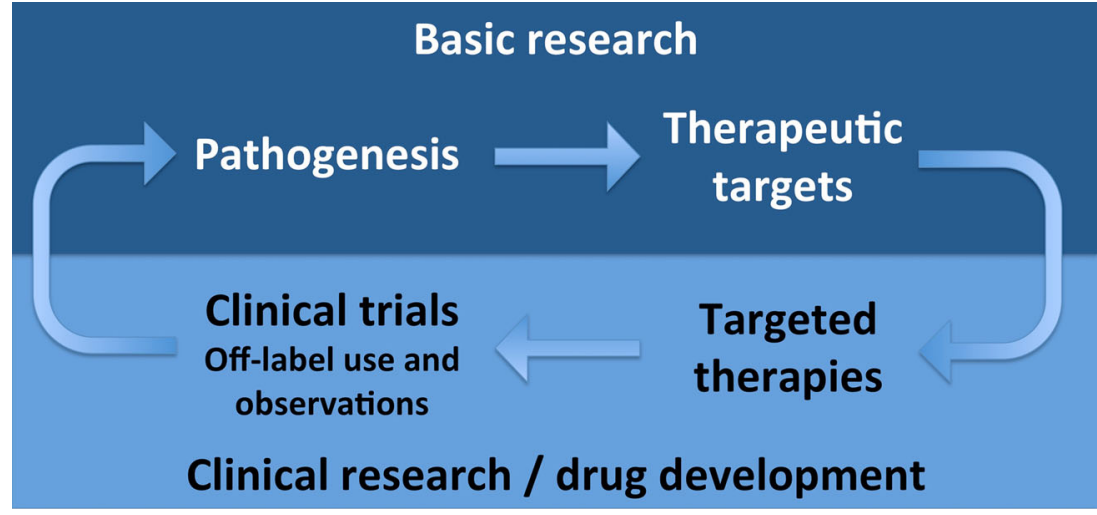

hidden potential of synergic therapy, where two or more targets with known synergic pathogenetic effects are targeted simultaneously to achieve a greater therapeutic effect. Lastly, we will discuss what we can learn by observing clinical outcomes of our patients. The advantages and disadvantages of large-scale clinical trials are compared with careful, detailed observations of small cohorts of patients treated with targeted therapies through the eyes of physicians and scientists with a profound understanding of the underlying pathomechanism.

\section{Targeted therapies for early and chronic cutaneous inflammation}

Most inflammatory skin diseases are chronic in nature, but the clinical course can range from relatively stable diseases such as stable plaque-type psoriasis to chronic-relapsing diseases with sudden exacerbations such as pustular psoriasis or atopic dermatitis [2, 3]. Clinical observation shows that diseases segregate into acute-onset/relapsing pattern vs. long-lasting, chronic courses, such as sometimes seen in psoriasis type I and II [4]. Sometimes, it seems to us that the former type can be more easily treated, while the latter patients' lesions are difficult to influence therapeutically. The triggers that initiate those two distinct patterns may be distinct as well. Indeed, sterile inflammation in the initiation phase of inflammatory skin disease is mediated by the innate immune system and can thus be classified as autoinflammatory $[5,6]$. Autoinflammation is driven by endogenous danger signals, metabolic mediators, as well as cells and cytokines of the innate immune system such as IL-1, IL-8, and TNF- $\alpha$. Late inflammation, on the other hand, is considered to be driven and maintained, respectively, by activated cells of the adaptive immune cells, mainly T cells in the case of cutaneous inflammation [1]. Therefore, cutaneous inflammation in skin disease can be viewed as consisting of two phases of overarching but distinct types of inflammation: (1) an autoinflammatory phase, driven by endogenous or exogenous triggers, mediated by the innate immune system, and implicated in initiating disease and (2) an autoimmune phase, which is initiated by these autoinflammatory events but mediated by the adaptive immune system. The autoimmune phase is considered to play the predominant role in chronic stable disease [6].

A typical example of such interplay between autoinflammatory and autoimmune inflammation in skin disease can be observed in plaque-type psoriasis (Fig. 2). According to the clever model of biphasic immune activation [6], psoriasis lesions are initiated by constantly repeated short bursts of innate inflammation, consisting of toll-like receptor activated dendritic cells, rapid release of cytokines of the IL-1 family, and recruitment of neutrophils. In a transitional period, T helper type 17 cells (Th17) are attracted and activated by dendritic cell (DC)-derived IL-23 and, likely together with neutrophils, release large amounts of IL-17 [1, 7]. Then, an immunological switch takes place with the dendritic cells starting to produce IFN- $\alpha$. This cytokine antagonizes IL-1 family member cytokines, suppresses the Th17 response, and initiates a classical Th1-dominated cytokine milieu with the influx of IFN- $\gamma$-producing Th1 cells and macrophages, thus heralding the beginning of the chronic stable stage of inflammation [8]. In this process, differentiation of Th1 cells is dependent on IL-12 produced by macrophages and DCs. Taken together, in classical psoriasis plaques, bursts of innate autoinflammation coexist with T-cell-driven autoimmune inflammation [6]. The corresponding histopathological features are infiltration of activated innate immune cells such as mast cells and neutrophils in developing psoriatic lesions and a predominance of activated $\mathrm{T}$ cells and macrophages in stable psoriasis lesions $[3,9,10]$. The corresponding clinical features are pustular eruptions for highly acute psoriasis and pitted nails due to recurrent neutrophil eruptions in the nail bed as a sign of recurrent local autoinflammation.

A similar dichotomous or biphasic view on the inflammatory process can be applied to atopic dermatitis: [2]. In the initiation phase of allergic skin inflammation, exogenous triggers such as allergens (e.g., house dust mites), viruses, and bacteria (e.g., Staphylococcus aureus) induce the production of innate cytokines like thymic stromal lymphopoietin (TSLP) and IL-33 from keratinocytes [11] which in turn induce secretion of IL-5 and IL-13 from innate lymphoid cells (ILCs) and 


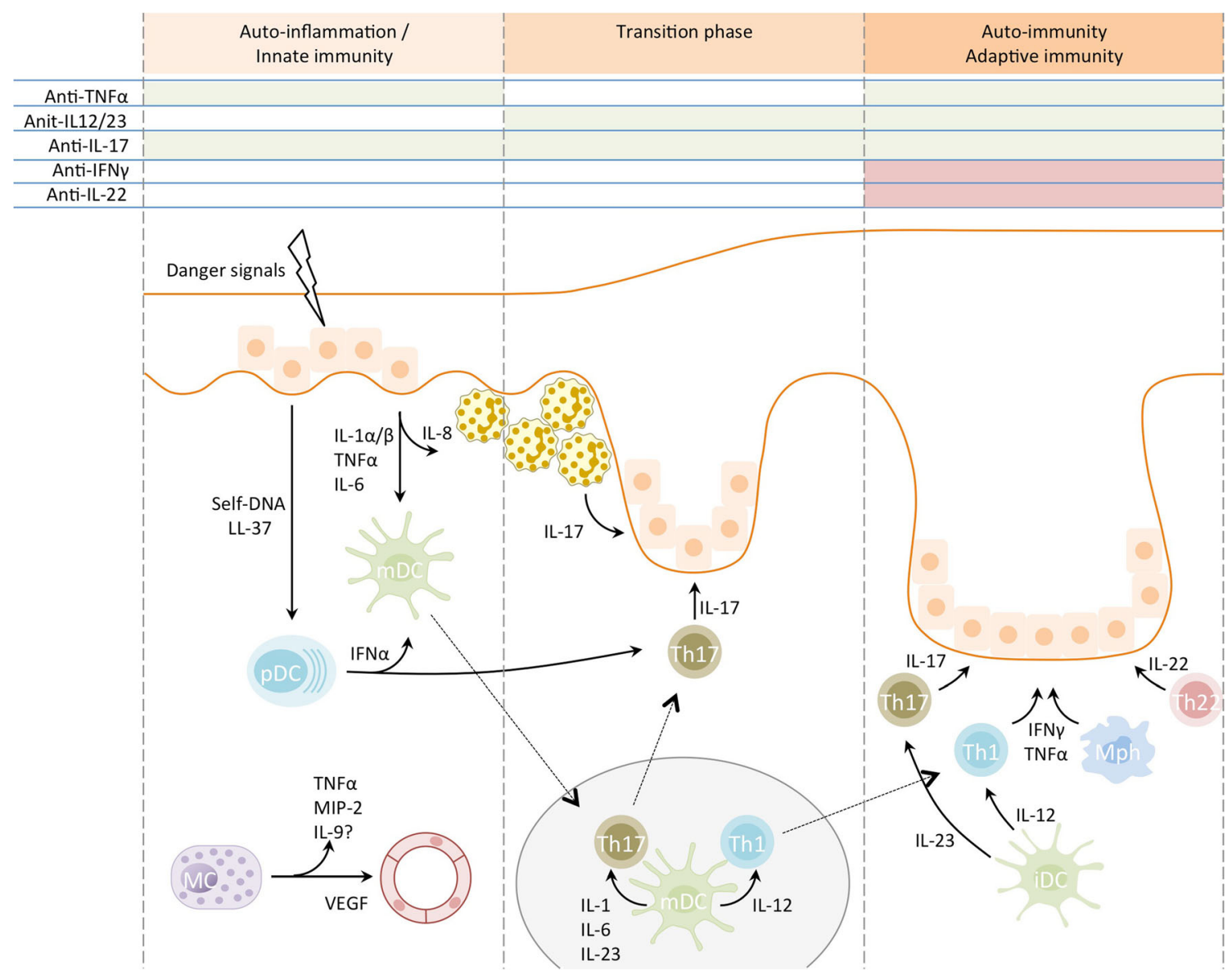

Fig. 2 Three phases of the immune mechanisms driving inflammatory disease

IL-10 from Langerhans cells $[12,13]$. This initial innate immune response triggers a mixed innate/adaptive transitional phase where Th2 cells are activated to produce more IL-4, IL-13, and IL-31 [13, 14], B cells undergo isotype class switch to produce IgE antibodies, and eosinophils and basophils start to infiltrate the skin. Finally, in the chronic stage of atopic dermatitis, the inflammatory picture is dominated by adaptive immunity with Th22 cells and Th1 cells producing IL-22 and IFN- $\gamma$, respectively. The differentiation and maintenance of these T cell subsets are thought be maintained by IL-12 secreting myeloid dendritic cells ( $\mathrm{mDCs}$ ), which are also abundantly found in the immune infiltrate of chronic AD [1].

As for psoriasis, these sequential inflammatory processes are also reflected in the histopathological and clinical presentation: histopathology of acute AD shows epidermal changes with intercellular edema (spongiosis) and activated LCs and a beginning dermal infiltrate consisting of mast cells, T cells, and monocytes/macrophages. In chronic lesions, macrophages/dendritic cells and $\mathrm{T}$ cells dominate the dermal infiltrate, with a few eosinophils and non-degranulated mast cells [15]. Clinically, early AD lesions are characterized by inflammatory papules and vesicles on a background of erythema, whereas chronic lesions present with infiltrated, fibrotic plaques with scales and lichenification [16].

Taken together, both in psoriasis and $\mathrm{AD}$, the immunopathologic process is characterized by distinct but partially overlapping inflammatory phases, namely an early autoinflammatory phase orchestrated by the innate immune system and a chronic autoimmune phase, dominated by cells and cytokines of the adaptive immune system.

Today, a plethora of targeted therapies to inhibit multiple of the abovementioned inflammatory pathways are either approved or currently in clinical trials. For psoriasis, the approved therapies with long successful clinical track records target TNF- $\alpha$ or IL-12/23p 40 . This group of highly effective biologics was recently joined by monoclonal antibodies targeting IL-17 or its receptor, showing impressive therapeutic efficacy. In contrast, monoclonal antibodies targeting IL-22 or IFN- $\gamma$ have shown disappointing results in clinical trials in psoriasis, failing to induce major improvements in most patients [1, 17]. This divergent therapeutic efficiency of inhibiting distinct inflammatory pathways now provides the basis for validation of established pathogenesis models and reflections on the true contributions of these molecules to pathogenesis. For instance, the striking difference in the 
ability to inhibit psoriatic inflammation of anti-IL-17 compared to anti-IFN- $\gamma$ antibodies, despite similar expression levels in situ of these two cytokines [18], raises questions on the respective pathogenetic contribution of these two cytokines. A straightforward explanation, of course, attributes a lesser pathogenic role to the IL-12/Th1/IFN- $\gamma$ axis and a central pro-inflammatory role to the IL-23/Th17/IL-17 axis, thus elegantly explaining the diverging clinical efficiency of blocking either pathway. However, given the manifold and well-established pro-inflammatory effects of IFN- $\gamma$ on immune and non-immune cells [19], many of which have been intimately linked to psoriasis pathogenesis [20,21], the true answer might be more complicated. Similar reflections apply to the cytokine IL-22. Translational research has identified IL22 as a key proinflammatory cytokine in psoriatic skin inflammation linking immune and epithelial cells [22], yet antagonism of this cytokine does not seem to be very efficient in improving the skin condition of psoriasis patients [1]. Again, it can be postulated that IL-22 does therefore not play a major pathogenic role, but a more careful look at emerging models of cutaneous inflammation might provide new insights.

One viewpoint under which these observations can be dissected is the concept of early and chronic or autoinflammatory and autoimmune inflammation, as introduced above. Looking at the outstanding clinical efficacy of neutralizing TNF- $\alpha$, IL$12 / 23$ p 40 or IL-17 and the lack of benefit from blocking IFN$\mathrm{g}$ or IL-22, it could also be imagined that, to achieve therapeutic effect, it is necessary to inhibit inflammatory signals that act in both the early and the late phase of inflammation (Fig. 2), or to inhibit signals that play an intricate role in bridging these two phases. For example, TNF- $\alpha$ is expressed in the very early phases of innate inflammation by stressed keratinocytes but remains a key cytokine in the chronic phase, where it is abundantly produced by Th1 cells, macrophages, and activated keratinocytes. Thus, antagonizing TNF- $\alpha$ will suppress both the early innate and the late adaptive immune response, leading to downregulation of initiating as well as maintaining inflammatory signals and therefore to successful treatment of psoriasis. Similarly, DC-derived IL-12/23p40 is involved in bridging innate and adaptive inflammation, as it is expressed after DCs sense innate danger signals and then leads to activation of an adaptive Th1 and Th17 response. Therefore, by blocking IL-12/23p 40 , interference with both the autoimmune and the autoinflammatory phase is established and, consequently, successful treatment of psoriatic inflammation is observed clinically. These reflections may also apply to the high efficacy of neutralizing IL-17 signaling in psoriasis, as IL-17 is increasingly understood to be an intricate part of both the early innate and the late adaptive immune response [7, 23].

Under the same view, the lack of therapeutic benefit from blocking IFN-y or IL-22 signals in psoriasis could be explained by their predominant involvement in late autoimmune but not early autoinflammatory phase of inflammation [24].
As a consequence, ongoing innate stimulation and positive feed-forward loops are not inhibited and continue to trigger adaptive inflammation. The concept that abrogation of both phases of inflammation is necessary to successfully treat psoriasis is further supported by the conspicuous absence of reports showing clinical benefit from blocking early innate mediators such as IFN- $\alpha$ (MEDI-545) and IL-1 (by anakinra for $\alpha \beta$, canakinumab $(\beta)$, rilonacept $(\beta)$ and MABp1 $(\alpha)$ ), despite the mentioned biologics to neutralize these signals with proven clinical efficacy in inflammatory skin diseases that are characterized by dominating innate immune activation such as neutrophil dermatoses and pustular psoriasis [25-27].

The same concept can be used to analyze efficacy of targeted therapies in atopic dermatitis, although clinical experience with these drugs is considerably smaller than in psoriasis and clinical trials have just started on a broader scale recently [28]. Therefore, only data from clinical trials on neutralizing antibodies against IL-5 (mepolizumab) $[29,30]$ and $\mathrm{IL}-4 \mathrm{R} \alpha$ (dupilumab) $[31,32]$ are available as well as a few reports from case series using anti-IL-6R and anti-CD20 antibodies in atopic dermatitis $[33,34]$. In clinical trials, anti-IL-5 therapy did not show any therapeutic effects whereas anti-IL$4 \mathrm{R} \alpha$ treatment, which interferes with both IL- 4 and IL-13 signaling, induced marked and rapid improvement of atopic dermatitis. In the model of early and late inflammation, these diverging clinical effects can be explained by the different targets of the blocked cytokines. In atopic dermatitis, IL-5 exerts its effects in early inflammation, predominantly by promoting accumulation and activation of eosinophils in the skin, albeit it being expressed by cells of both the innate and adaptive immune system and it having effects on isotype class switching in B cells. Thus, neutralization of IL-5 will mainly interfere with attraction and activation of eosinophils in early innate inflammation but will fail to limit chronic adaptive immune circuits. In contrast, dupilumab blocks the shared alpha subunit of the IL-4/IL-13 receptor and thus inhibits proinflammatory signals in all cells that express either receptor. These include innate cells such as keratinocytes, dendritic cells, innate lymphoid cells, as well as adaptive immune cells such as $\mathrm{T}$ cells of different subsets and $\mathrm{B}$ cells. Therefore, blocking the IL-4/IL-13 receptor profoundly dampens innate as well as adaptive inflammation in atopic dermatitis and therefore, according to the model of bimodal immune activation in cutaneous inflammation, shows great therapeutic effect. This hypothesis is further supported in atopic dermatitis by the clinical benefit of interrupting IL-6R signaling, as IL-6 is known for its regulatory role in innate and adaptive immunity [34, 35]. It will be highly interesting to see the outcome of ongoing clinical trials in atopic dermatitis with targeted therapeutics against mediators of innate inflammation (IL-33, TSLP) and mixed innate/adaptive inflammation (IL-31, IL-22). 
Another cytokine that merits attention along these lines is IL-9. Although discovered 20 years ago, it remains one of the more enigmatic cytokines so far and its cellular source, function, and targets remain incompletely understood [36]. However, a growing body of evidence points towards a role in early allergic but not late inflammatory processes, with remarkably transient IL-9 expression early after cellular activation [37-40]. Therefore, IL-9 might be a model cytokine with a unique role in early transient immune activation but no importance for chronic inflammation. In accordance, the only clinical trial attempting at blocking IL-9 in human chronic asthma has failed to show efficacy [41].

In summary, the clinical efficacy of blocking distinct inflammatory signals in cutaneous disease with bimodal immune activation might not solely be determined by the involved pathways, but also by their ability to interfere with both the autoinflammatory and the autoimmune phase of skin inflammation. If this is the case, antagonism of early innate cytokines such as IL-1 might be more suitable to prevent new flares of psoriasis rather than to treat established plaques [6] and inhibition of keratinocyte-derived signals like TSLP or IL-33 might be more suitable to treat subclinical inflammation rather than established atopic dermatitis. Questions like these have so far not been addressed in clinical trials and remain to be elucidated by curious clinicians with both their patient's wellbeing and pathomechanistic reflections in mind.

\section{Immune deviation instead of immune blockade?}

The simple concept of stopping inflammation by silencing immune signals or even destroying their cells of origin could in the future be replaced by more elegant approaches. If we assume that inflammatory conditions arise due to misguided, normally beneficial signals, one could attempt to steer the immune metabolism back in its normal and healthy channels.

There are a series of remarkable studies along these lines that have all been performed more than 10 years ago [42-44]. It appears that with the advent of monoclonal antibodies against cytokines, this idea has moved into the background, despite impressive clinical effects observed in these early studies. However, there are important lessons that likely can be learned from them that will also help understand and even predict clinical phenomena that arise or likely will arise in patients undergoing targeted therapy. On a very basic level, these studies have taught us that established inflammatory equilibria in skin lesions can be toppled by manipulating the pathways that stabilize them. For instance, treatment of psoriasis patients with recombinant IL-4 markedly improved psoriasis and induced pronounced skewing of intralesional cytokines towards a Th2 pattern while downregulating Th1/17 type inflammation [42]. Recently, the mechanism of this interesting phenomenon that works via IL-4 silencing IL-23 in antigen-presenting cells was demonstrated [45]. Similar observations were made in psoriasis patients when treated with the anti-inflammatory cytokines IL-10 or IL-11 [43, 44]. Further investigation of the dynamics and half-life of these phenomena will yield interesting information about the stability of immune deviating strategies. This could answer whether we may ever be able to attempt a definite cure of psoriasis and other conditions with, i.e., prolonged cytokine treatments or novel vaccinations that ideally would produce a long-lasting effect.

Pathologic immune deviation could also explain intriguing observations regularly made during clinical treatment of inflammatory dermatoses, such as sudden resistance to biologics without anti-drug antibodies, paradoxical psoriasis to TNF- $\alpha$ antagonists, and many more.

Not addressed at all in clinical studies as yet was the question of spatially localized immune cell swarms [46] in the skin and the rest of the immune system. It has been known for a while that skin-resident $\mathrm{T}$ cells are stable and form a separate compartment from blood [47]. Intriguing studies on coexisting atopic dermatitis and psoriasis in the same patients [48] demonstrated that even within the skin, swarms of immune cells do not necessarily intermingle but can create a stable biological mosaic. These swarms may stem from pathologic immune deviation that could theoretically be addressed with clever topical treatments.

Finally, instead of a "horizontal" deviation such as from Th1/17 to Th2, one can also follow a strategy of immune activation to de-activation with IL-10 and TGF- $\beta$, or even the other way around such as is regularly done with success in oncology with CTLA4 and PD1 [49, 50] antibodies.

\section{Multipronged intervention vs. monotherapy}

The current system of medical intervention with immunomodulating agents is primarily focused on the efficacy of single agents. This is easily understood when considering the complexity of performing studies with multiple compounds. However, in reality, the immune system is more complex and in most instances more than one signal is involved in creating or sustaining pathology. Therefore, it might be beneficial and efficacious to inhibit more than one cytokine during treatment. Were such a strategy be tested, it should first be shown that the target cytokines are indeed synergistic and not vertically arranged in a single pathway. Otherwise, the inhibition of the upstream cytokine could already (theoretically) achieve the maximum efficacy on its own, eliminating the need to inhibit the downstream cytokine.

Such synergistic combinations have already been analyzed in vitro, namely TNF- $\alpha$ and IL-17 and IL-1 and IL-23 [51, 52]. The cytokine combination was able to potentiate the result of the in vitro readout by several hundred-fold compared 
to what each single cytokine could achieve on its own-demonstrating the power of this strategy. It follows that also the success of cytokine inhibition could be improved dramatically by utilizing this effect. Very soon, such drugs will be in phase III clinical trials, including AbbVie's ABT-122 bispecific antibody against IL-17 and TNF- $\alpha$, Sanofi's tetravalent bispecific tandem immunoglobulin (TBTI) against IL-4 and IL-13, and others. Such fixed combination drugs inhibiting two or more cytokines fit very well in our current system of clinical trials and registration, even though the information of contribution to the final effect may be lost.

In dermatology, we have the unique opportunity to combine systemic drugs with topical agents. This field has been little investigated, with early surprising results, including temporary loss of efficacy by combining two monotherapies [53]. So far, interesting questions such as to the effect of systemic TNF-antagonism together with local calcineurin-inhibition have not yet been addressed.

\section{Treatments based on large randomized placebo-controlled trials vs. Sherlockian observatory approach}

Clinical medicine is both blessed and burdened with large randomized controlled trials (RCTs) for virtually every important intervention. These large and hugely costly studies are currently considered a sine qua non for drug registration. Unfortunately, they also have many disadvantages that we cannot exhaustively enumerate here. Evidence hierarchies place RCT at the top, which however should not lead to a black-or-white worldview and discounting of all other, non-RCT evidence. We are all aware that for practical reasons only a part, possibly not even the majority of all diseases, can be studied by RCTs. Evidence on the rarer diseases or subtypes of common conditions, very young and old patients, ethnic minorities and the like tends to come from non-RCT studies including case reports. Although all such evidence needs to be interpreted cautiously, as a whole we believe it to be often very useful, at least for clinical decision-making in the same type of nonstandardized situations that gave rise to the case reports. Table 1 includes a compilation of current evidence of case reports and clinical studies broken down according to dermatosis and treatment target. Outcomes of just one case or series are put in brackets. Collection of efficacy data of targeted treatments also reveals, perhaps most accurately of all approaches, the clinically relevant pathophysiology of each disease.

Case reports have the obvious disadvantage of publication bias of positive results, non-standardized treatment schemes, and missing placebo controls. To overcome these limitations, $\mathrm{N}$-of-1 [54] strategies could be promoted to replace widespread off-label use in dermatology. These are proper small trials that closely observe the effect of an intervention in a single patient and can even be performed as a randomized controlled study by giving verum and placebo sequentially. Strategies for generic ethical approval of such interventions could be generated, so that administrative constraints do not preclude clinicians from choosing this avenue of research.

Taken together, we believe that decision-making in common and well-studied situations such as moderate-to-severe plaque psoriasis should be based on RCT results and metaanalyses. In rarer, non-standard situations however, using evidence derived from lower-quality studies, especially with independently confirmed results, might be acceptable as well as this is often the only available source of information. In our specialty with more than 2000 mostly rare conditions, case reports could thus be considered worthwhile and clinically useful contributions as long as there are no RCT available.

\section{Conclusion}

The advent of targeted therapies for inflammatory skin disease has not only heralded an era where clinicians have manifold therapeutic options and patients benefit from unprecedented clinical efficacy, it has also opened new ways of investigating the pathogenesis underlying these complex skin conditions and of validating disease models that arise from basic research. Thanks to the well-defined molecular targets of these novel drugs, it is now possible to deduce pathomechanistic processes from clinical observations to an extent that has not been allowed by previous treatments with broad biological effects. In what can be called a "circle of induction and deduction," these insights continually feedback to and guide basic research which in turn results in the identification of novel drug targets that will eventually be tested in a clinical setting (Fig. 1). As a consequence, we are today witnessing a translational revolution of model inflammatory skin diseases, most prominently of psoriasis and atopic dermatitis [1]. The future will certainly bring further innovation and, based on large trials and huge efforts from the industry, improved and precisely tailored treatments for these frequent diseases. However, targeted therapies also hold great promise for rare inflammatory skin diseases, where medical and scientific advance mainly relies on the initiative of curious clinicians and scientists. In this setting, it seems promising to harvest the scientific potential of assessing targeted therapies in small trials where translational analysis, e.g., of sequential tissue samples before and under treatment are prone to yield a wealth of novel information on both disease mechanisms and mode of action of the investigated drug. Successful examples of such translational approaches are continuously published from all fields of dermatology and are likely to further shape the way we understand our patients and their treatments in the future [55]. 
Table 1 Evidence for efficacy of biologic agents for inflammatory dermatoses

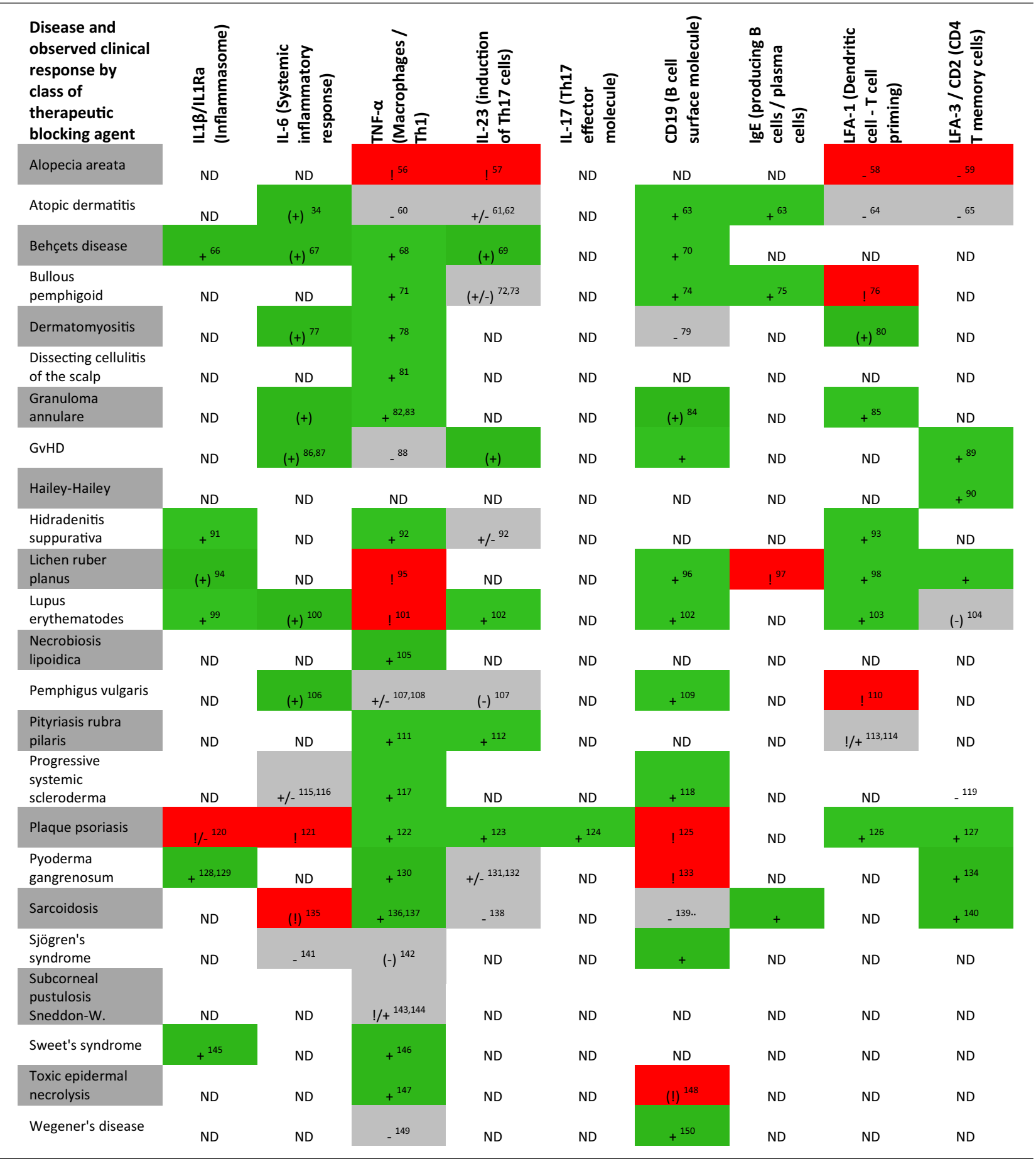

! blocking drug can elicit disease, () one case or series only, $N D$ no data

As the field of translational medicine continues to evolve and the number of available targeted therapies increases, we will undoubtedly see further refinements of current disease models. The concept of bimodal immune activation postulating that early inflammatory events are distinct from, but intimately linked to, later chronic inflammation has the potential to introduce different treatment modalities for patients with acute or chronic disease and to prompt the development of relapsepreventing therapeutics [6]. Animal models used in basic research can be validated by careful comparison with clinical studies of targeted therapies, thus assessing strengths and weaknesses of the respective models. Combined inhibition of targets with synergistic pathogenic potential will likely add highly effective treatment options for patients with recalcitrant disease. 
In summary, targeted therapies have profoundly influenced not only the treatment but also the understanding of psoriasis and are likely to have a similar impact on other model inflammatory skin diseases such as atopic dermatitis. Further translational research in this field holds the promise that similar developments will also take place in less common inflammatory skin diseases, making the impressive therapeutic potential of targeted drugs available to many more patients while teaching their doctors valuable lessons about the underlying disease.

Financial Disclosure None of the authors have relevant financial relationships to this manuscript.

\section{References}

1. Noda S, Krueger JG, Guttman-Yassky E (2015) The translational revolution and use of biologics in patients with inflammatory skin diseases. J Allergy Clin Immunol 135:324-336

2. Bieber T (2008) Atopic dermatitis. N Engl J Med 358:1483-1494

3. Nestle FO, Kaplan DH, Barker J (2009) Psoriasis. N Engl J Med 361:496-509

4. Henseler T, Christophers E (1985) Psoriasis of early and late onset: characterization of two types of psoriasis vulgaris. J Am Acad Dermatol 13:450-456

5. van Kempen TS, Wenink MH, Leijten EF, Radstake TR, Boes M. Perception of self: distinguishing autoimmunity from autoinflammation. Nat Rev Rheumatol 2015

6. Christophers E, Metzler G, Rocken M (2014) Bimodal immune activation in psoriasis. Br J Dermatol 170:59-65

7. Kakeda M, Schlapbach C, Danelon G et al (2014) Innate immune cells express IL-17A/F in acute generalized exanthematous pustulosis and generalized pustular psoriasis. Arch Dermatol Res 306:933-938

8. Nestle FO, Conrad C, Tun-Kyi A et al (2005) Plasmacytoid predendritic cells initiate psoriasis through interferon-alpha production. J Exp Med 202:135-143

9. Schubert C, Christophers E (1985) Mast cells and macrophages in early relapsing psoriasis. Arch Dermatol Res 277:352-358

10. Biedermann T, Kneilling M, Mailhammer R et al (2000) Mast cells control neutrophil recruitment during $\mathrm{T}$ cell-mediated delayed-type hypersensitivity reactions through tumor necrosis factor and macrophage inflammatory protein 2. J Exp Med 192: $1441-1452$

11. Tamagawa-Mineoka R, Okuzawa Y, Masuda K, Katoh N (2014) Increased serum levels of interleukin 33 in patients with atopic dermatitis. J Am Acad Dermatol 70:882-888

12. Kim BS, Siracusa MC, Saenz SA et al (2013) TSLP elicits IL-33independent innate lymphoid cell responses to promote skin inflammation. Sci Transl Med 5:170ra16

13. Rank MA, Kobayashi T, Kozaki H, Bartemes KR, Squillace DL, Kita H (2009) IL-33-activated dendritic cells induce an atypical TH2-type response. J Allergy Clin Immunol 123:1047-1054

14. Maier E, Werner D, Duschl A, Bohle B, Horejs-Hoeck J (2014) Human Th2 but not Th9 cells release IL-31 in a STAT6/NFkappaB-dependent way. J Immunol (Baltimore, Md : 1950) 193: 645-654

15. Bieber T (2010) Atopic dermatitis. Ann Dermatol 22:125-137

16. Eichenfield LF, Tom WL, Chamlin SL et al (2014) Guidelines of care for the management of atopic dermatitis: section 1. Diagnosis and assessment of atopic dermatitis. J Am Acad Dermatol 70:338 351

17. Harden JL, Johnson-Huang LM, Chamian MF et al (2015) Humanized anti-IFN-gamma (HuZAF) in the treatment of psoriasis. J Allergy Clin Immunol 135:553-556

18. Guttman-Yassky E, Lowes MA, Fuentes-Duculan J et al (2007) Major differences in inflammatory dendritic cells and their products distinguish atopic dermatitis from psoriasis. J Allergy Clin Immunol 119:1210-1217

19. Lazarevic V, Glimcher LH (2011) T-bet in disease. Nat Immunol 12:597-606

20. Johnson-Huang LM, Suarez-Farinas M, Pierson KC et al (2012) A single intradermal injection of IFN-gamma induces an inflammatory state in both non-lesional psoriatic and healthy skin. J Invest Dermatol 132:1177-1187

21. Conrad C, Boyman O, Tonel G et al (2007) Alpha1beta1 integrin is crucial for accumulation of epidermal T cells and the development of psoriasis. Nat Med 13:836-842

22. Perera GK, Ainali C, Semenova E et al (2014) Integrative biology approach identifies cytokine targeting strategies for psoriasis. Sci Transl Med 6:223ra22

23. Taylor PR, Roy S, Leal SM Jr et al (2014) Activation of neutrophils by autocrine IL-17A-IL-17RC interactions during fungal infection is regulated by IL-6, IL-23, RORgammat and dectin-2. Nat Immunol 15:143-151

24. Guttman-Yassky E, Nograles KE, Krueger JG (2011) Contrasting pathogenesis of atopic dermatitis and psoriasis - part II: immune cell subsets and therapeutic concepts. J Allergy Clin Immunol 127:1420-1432

25. Mansouri B, Richards L, Menter A (2014) Treatment of two patients with generalized pustular psoriasis with the interleukin1 beta inhibitor gevokizumab. Br J Dermatol

26. Saggini A, Chimenti S, Chiricozzi A (2014) IL-6 as a druggable target in psoriasis: focus on pustular variants. J Immunol Res 2014:964069

27. Prat L, Bouaziz JD, Wallach D, Vignon-Pennamen MD, Bagot M (2014) Neutrophilic dermatoses as systemic diseases. Clin Dermatol 32:376-388

28. Acosta-Rodriguez EV, Napolitani G, Lanzavecchia A, Sallusto F (2007) Interleukins 1beta and 6 but not transforming growth factor-beta are essential for the differentiation of interleukin 17producing human T helper cells. Nat Immunol 8:942-949

29. Oldhoff JM, Darsow U, Werfel T et al (2006) No effect of anti-interleukin-5 therapy (mepolizumab) on the atopy patch test in atopic dermatitis patients. Int Arch Allergy Immunol 141:290-294

30. Oldhoff JM, Darsow U, Werfel T et al (2005) Anti-IL-5 recombinant humanized monoclonal antibody (mepolizumab) for the treatment of atopic dermatitis. Allergy 60:693-696

31. Hamilton JD, Suarez-Farinas M, Dhingra N et al (2014) Dupilumab improves the molecular signature in skin of patients with moderate-to-severe atopic dermatitis. J Allergy Clin Immunol 134:1293-1300

32. Beck LA, Thaci D, Hamilton JD et al (2014) Dupilumab treatment in adults with moderate-to-severe atopic dermatitis. N Engl J Med 371:130-139

33. Simon D, Hosli S, Kostylina G, Yawalkar N, Simon HU (2008) Anti-CD20 (rituximab) treatment improves atopic eczema. J Allergy Clin Immunol 121:122-128

34. Navarini AA, French LE, Hofbauer GF (2011) Interrupting IL-6receptor signaling improves atopic dermatitis but associates with bacterial superinfection. J Allergy Clin Immunol 128:1128-1130

35. Hunter CA, Jones SA (2015) IL-6 as a keystone cytokine in health and disease. Nat Immunol 16:448-457

36. Schmitt E, Klein M, Bopp T (2014) Th9 cells, new players in adaptive immunity. Trends Immunol 35:61-68 
37. Licona-Limon P, Henao-Mejia J, Temann AU et al (2013) Th9 cells drive host immunity against gastrointestinal worm infection. Immunity 39:744-757

38. Schlapbach C, Gehad A, Yang C et al (2014) Human TH9 cells are skin-tropic and have autocrine and paracrine proinflammatory capacity. Sci Transl Med 6:219ra8

39. Turner JE, Morrison PJ, Wilhelm C et al (2013) IL-9-mediated survival of type 2 innate lymphoid cells promotes damage control in helminth-induced lung inflammation. J Exp Med 210:2951-2965

40. Wilhelm C, Hirota K, Stieglitz B et al (2011) An IL-9 fate reporter demonstrates the induction of an innate IL-9 response in lung inflammation. Nat Immunol 12:1071-1077

41. Oh CK, Leigh R, McLaurin KK, Kim K, Hultquist M, Molfino NA (2013) A randomized, controlled trial to evaluate the effect of an anti-interleukin-9 monoclonal antibody in adults with uncontrolled asthma. Respir Res 14:93

42. Ghoreschi K, Thomas P, Breit S et al (2003) Interleukin-4 therapy of psoriasis induces Th2 responses and improves human autoimmune disease. Nat Med 9:40-46

43. Reich K, Garbe C, Blaschke V et al (2001) Response of psoriasis to interleukin-10 is associated with suppression of cutaneous type 1 inflammation, downregulation of the epidermal interleukin-8/ CXCR2 pathway and normalization of keratinocyte maturation. J Invest Dermatol 116:319-329

44. Trepicchio WL, Ozawa M, Walters IB et al (1999) Interleukin-11 therapy selectively downregulates type I cytokine proinflammatory pathways in psoriasis lesions. J Clin Invest 104:1527-1537

45. Guenova E, Skabytska Y, Hoetzenecker W et al (2015) IL-4 abrogates $\mathrm{T}(\mathrm{H}) 17$ cell-mediated inflammation by selective silencing of IL-23 in antigen-presenting cells. Proc Natl Acad Sci U S A 112: 2163-2168

46. Lammermann T, Afonso PV, Angermann BR et al (2013) Neutrophil swarms require LTB4 and integrins at sites of cell death in vivo. Nature 498:371-375

47. Clark RA (2011) Gone but not forgotten: lesional memory in psoriatic skin. J Invest Dermatol 131:283-285

48. Eyerich S, Onken AT, Weidinger S et al (2011) Mutual antagonism of T cells causing psoriasis and atopic eczema. N Engl J Med 365: 231-238

49. Kroemer G, Galluzzi L (2015) Combinatorial immunotherapy with checkpoint blockers solves the problem of metastatic melanoma-an exclamation sign with a question mark. Oncoimmunology 4:e1058037

50. Wolchok JD, Kluger H, Callahan MK et al (2013) Nivolumab plus ipilimumab in advanced melanoma. N Engl J Med 369:122-133

51. Chiricozzi A, Guttman-Yassky E, Suarez-Farinas M et al (2011) Integrative responses to IL-17 and TNF-alpha in human keratinocytes account for key inflammatory pathogenic circuits in psoriasis. J Invest Dermatol 131:677-687

52. Sutton CE, Lalor SJ, Sweeney CM, Brereton CF, Lavelle EC, Mills KH (2009) Interleukin-1 and IL-23 induce innate IL-17 production from gammadelta T cells, amplifying Th17 responses and autoimmunity. Immunity $31: 331-341$

53. Thaci D, Ortonne JP, Chimenti S et al (2010) A phase IIIb, multicentre, randomized, double-blind, vehicle-controlled study of the efficacy and safety of adalimumab with and without calcipotriol/betamethasone topical treatment in patients with moderate to severe psoriasis: the BELIEVE study. Br J Dermatol 163: 402-411

54. Tsapas A, Matthews DR (2009) Using N-of-1 trials in evidencebased clinical practice. JAMA 301:1022-1023, author reply 3

55. Clark RA, Watanabe R, Teague JE et al (2012) Skin effector memory T cells do not recirculate and provide immune protection in alemtuzumab-treated CTCL patients. Sci Transl Med 4:117ra7

56. Hernandez MV, Nogues S, Ruiz-Esquide V, Alsina M, Canete JD, Sanmarti R (2009) Development of alopecia areata after biological therapy with TNF-alpha blockers: description of a case and review of the literature. Clin Exp Rheumatol 27:892-893

57. Tauber M, Beneton N, Reygagne P, Bachelez H, Viguier M (2013) Alopecia areata developing during ustekinumab therapy: report of two cases. Eur J Dermatol : EJD 23:912-913

58. Price VH, Hordinsky MK, Olsen EA et al (2008) Subcutaneous efalizumab is not effective in the treatment of alopecia areata. $\mathrm{J}$ Am Acad Dermatol 58:395-402

59. Strober BE, Menon K, McMichael A et al (2009) Alefacept for severe alopecia areata: a randomized, double-blind, placebocontrolled study. Arch Dermatol 145:1262-1266

60. Wright RC (2003) Atopic dermatitis-like eruption precipitated by infliximab. J Am Acad Dermatol 49:160-161

61. Samorano LP, Hanifin JM, Simpson EL, Leshem YA (2014) Inadequate response to ustekinumab in atopic dermatitis - a report of two patients. J Eur Acad Dermatol Venereol : JEADV

62. Fernandez-Anton Martinez MC, Alfageme Roldan F, Ciudad Blanco C, Suarez FR (2014) Ustekinumab in the treatment of severe atopic dermatitis: a preliminary report of our experience with 4 patients. Actas Dermosifiliogr 105:312-313

63. Sanchez-Ramon S, Eguiluz-Gracia I, Rodriguez-Mazariego ME et al (2013) Sequential combined therapy with omalizumab and rituximab: a new approach to severe atopic dermatitis. J Investig Allergol Clin Immunol 23:190-196

64. Ibler K, Dam TN, Gniadecki R, Kragballe K, Jemec GB, Agner T (2010) Efalizumab for severe refractory atopic eczema: retrospective study on 11 cases. J Eur Acad Dermatol Venereol : JEADV 24:837-839

65. Moul DK, Routhouska SB, Robinson MR, Korman NJ (2008) Alefacept for moderate to severe atopic dermatitis: a pilot study in adults. J Am Acad Dermatol 58:984-989

66. Cantarini L, Lopalco G, Caso F et al (2015) Effectiveness and tuberculosis-related safety profile of interleukin-1 blocking agents in the management of Behcet's disease. Autoimmun Rev 14:1-9

67. Addimanda O, Pipitone N, Pazzola G, Salvarani C (2015) Tocilizumab for severe refractory neuro-Behcet: three cases IL-6 blockade in neuro-Behcet. Semin Arthritis Rheum 44:472-475

68. Vallet H, Riviere S, Sanna A et al (2015) Efficacy of anti-TNF alpha in severe and/or refractory Behcet's disease: multicenter study of 124 patients. J Autoimmun 62:67-74

69. Baerveldt EM, Kappen JH, Thio HB, van Laar JA, van Hagen PM, Prens EP (2013) Successful long-term triple disease control by ustekinumab in a patient with Behcet's disease, psoriasis and hidradenitis suppurativa. Ann Rheum Dis 72:626-627

70. Davatchi F, Shams H, Rezaipoor M et al (2010) Rituximab in intractable ocular lesions of Behcet's disease; randomized singleblind control study (pilot study). Int J Rheum Dis 13:246-252

71. Ricci M, Zauli S, Zelante A, Trevisani L, Virgili A, Bettoli V (2014) Bullous pemphigoid occurring under anti-tumor necrosis factor-alpha therapy. Int J Color Dis 29:1573-1574

72. Nakayama C, Fujita Y, Watanabe M, Shimizu H (2015) Development of bullous pemphigoid during treatment of psoriatic onycho-pachydermo periostitis with ustekinumab. J Dermatol

73. Majima Y, Yagi H, Tateishi C et al (2013) A successful treatment with ustekinumab in a case of antilaminin-gammal pemphigoid associated with psoriasis. Br J Dermatol 168:1367-1369

74. Cho YT, Chu CY, Wang LF (2015) First-line combination therapy with rituximab and corticosteroids provides a high complete remission rate in moderate-to-severe bullous pemphigoid. $\mathrm{Br} \mathrm{J}$ Dermatol 173:302-304

75. Yu KK, Crew AB, Messingham KA, Fairley JA, Woodley DT (2014) Omalizumab therapy for bullous pemphigoid. J Am Acad Dermatol 71:468-474

76. Monnier-Murina K, Du Thanh A, Merlet-Albran S, Guillot B, Dereure O (2009) Bullous pemphigoid occurring during 
efalizumab treatment for psoriasis: a paradoxical auto-immune reaction? Dermatology (Basel, Switzerland) 219:89-90

77. Kondo M, Murakawa Y, Matsumura T et al (2014) A case of overlap syndrome successfully treated with tocilizumab: a hopeful treatment strategy for refractory dermatomyositis? Rheumatology (Oxford) 53:1907-1908

78. Riley P, McCann LJ, Maillard SM, Woo P, Murray KJ, Pilkington CA (2008) Effectiveness of infliximab in the treatment of refractory juvenile dermatomyositis with calcinosis. Rheumatology (Oxford) 47:877-880

79. Oddis CV, Reed AM, Aggarwal R et al (2013) Rituximab in the treatment of refractory adult and juvenile dermatomyositis and adult polymyositis: a randomized, placebo-phase trial. Arthritis Rheum 65:314-324

80. Huber A, Gaffal E, Bieber T, Tuting T, Wenzel J (2006) Treatment of recalcitrant dermatomyositis with efalizumab. Acta Derm Venereol 86:254-255

81. Navarini AA, Trueb RM (2010) 3 cases of dissecting cellulitis of the scalp treated with adalimumab: control of inflammation within residual structural disease. Arch Dermatol 146:517-520

82. Amy de la Breteque M, Saussine A, Rybojad M, et al.(2014) Infliximab in recalcitrant granuloma annulare. Int J Dermatol

83. Murdaca G, Colombo BM, Barabino G, Caiti M, Cagnati P, Puppo F (2010) Anti-tumor necrosis factor-alpha treatment with infliximab for disseminated granuloma annulare. Am J Clin Dermatol 11:437-439

84. Shah BK, Hewett Y, Peterson A, Tretheway D (2014) Resolution of granuloma annulare following treatment with bendamustine and rituximab in a patient with follicular lymphoma: a serendipitous finding. J Postgrad Med 60:406-408

85. Goffe BS (2004) Disseminated granuloma annulare resolved with the T-cell modulator efalizumab. Arch Dermatol 140: $1287-1288$

86. Hellwig Y, Yoo YE, Ress ML, et al. (2015) Fulminant skin GvHD with a cytokine pattern resemblant of cytokine release syndrome successfully treated with multimodal immunosuppression including tocilizumab. Pediatr Blood Cancer

87. Kennedy GA, Varelias A, Vuckovic S et al (2014) Addition of interleukin-6 inhibition with tocilizumab to standard graftversus-host disease prophylaxis after allogeneic stem-cell transplantation: a phase 1/2 trial. Lancet Oncol 15:1451-1459

88. Couriel DR, Saliba R, de Lima M et al (2009) A phase III study of infliximab and corticosteroids for the initial treatment of acute graft-versus-host disease. Biol Blood Marrow Transplant 15: 1555-1562

89. Shapira MY, Resnick IB, Bitan M et al (2005) Rapid response to alefacept given to patients with steroid resistant or steroid dependent acute graft-versus-host disease: a preliminary report. Bone Marrow Transplant 36:1097-1101

90. Hurd DS, Johnston C, Bevins A (2008) A case report of HaileyHailey disease treated with alefacept (Amevive). Br J Dermatol 158:399-401

91. Leslie KS, Tripathi SV, Nguyen TV, Pauli M, Rosenblum MD (2014) An open-label study of anakinra for the treatment of moderate to severe hidradenitis suppurativa. J Am Acad Dermatol 70: 243-251

92. Martin-Ezquerra G, Masferrer E, Masferrer-Niubo M et al (2015) Use of biological treatments in patients with hidradenitis suppurativa. J Eur Acad Dermatol Venereol : JEADV 29:56-60

93. Strober BE, Kim C, Siu K (2007) Efalizumab for the treatment of refractory hidradenitis suppurativa. J Am Acad Dermatol 57: 1090-1091

94. Cohen PR, Kurzrock R (2014) Anakinra-responsive lichen planus in a woman with Erdheim-Chester disease: a therapeutic enigma. Dermatol Online J 20:21241
95. Asarch A, Gottlieb AB, Lee J et al (2009) Lichen planus-like eruptions: an emerging side effect of tumor necrosis factor-alpha antagonists. J Am Acad Dermatol 61:104-111

96. Heelan K, McAleer MA, Roche L, McCreary C, Murphy M (2015) Intractable erosive lichen planus treated successfully with rituximab. Br J Dermatol 172:538-540

97. Seeborg FO, Rihal PS, Czelusta A, Sanchez R, Hanson IC (2009) Lichen planus associated with omalizumab administration in an adult with allergic asthma. Ann Allergy Asthma Immunol 102: 349-351

98. Heffernan MP, Smith DI, Bentley D, Tabacchi M, Graves JE (2007) A single-center, open-label, prospective pilot study of subcutaneous efalizumab for oral erosive lichen planus. J Drugs Dermatol : JDD 6:310-314

99. Moosig F, Zeuner R, Renk C, Schroder JO (2004) IL-1RA in refractory systemic lupus erythematosus. Lupus 13:605-606

100. Makol A, Gibson LE, Michet CJ (2012) Successful use of interleukin 6 antagonist tocilizumab in a patient with refractory cutaneous lupus and urticarial vasculitis. J Clin Rheumatol 18:92-95

101. Subramanian S, Yajnik V, Sands BE, Cullen G, Korzenik JR (2011) Characterization of patients with infliximab-induced lupus erythematosus and outcomes after retreatment with a second antiTNF agent. Inflamm Bowel Dis 17:99-104

102. De Souza A, Ali-Shaw T, Strober BE, Franks AG Jr (2011) Successful treatment of subacute lupus erythematosus with ustekinumab. Arch Dermatol 147:896-898

103. Navarini AA, Kerl K, French LE, Trueb RM (2010) Control of widespread hypertrophic lupus erythematosus with T-cell-directed biologic efalizumab. Dermatology (Basel, Switzerland) 220:249-253

104. Berthelot C, Nash J, Duvic M (2007) Coexistent psoriasis and lupus erythematosus treated with alefacept. Am J Clin Dermatol 8:47-50

105. Hertl MS, Haendle I, Schuler G, Hertl M (2005) Rapid improvement of recalcitrant disseminated granuloma annulare upon treatment with the tumour necrosis factor-alpha inhibitor, infliximab. Br J Dermatol 152:552-555

106. Caso F, Iaccarino L, Bettio S et al (2013) Refractory pemphigus foliaceus and Behcet's disease successfully treated with tocilizumab. Immunol Res 56:390-397

107. Jacobi A, Shuler G, Hertl M (2005) Rapid control of therapyrefractory pemphigus vulgaris by treatment with the tumour necrosis factor-alpha inhibitor infliximab. Br J Dermatol 153:448-449

108. Hall RP 3rd, Fairley J, Woodley D et al (2015) A multicentre randomized trial of the treatment of patients with pemphigus vulgaris with infliximab and prednisone compared with prednisone alone. Br J Dermatol 172:760-768

109. Kanwar AJ, Vinay K, Sawatkar GU et al (2014) Clinical and immunological outcomes of high- and low-dose rituximab treatments in patients with pemphigus: a randomized, comparative, observer-blinded study. Br J Dermatol 170:1341-1349

110. Santos-Juanes J, Coto-Segura P, Saavedra J, Laviano S, Galache C (2009) Development of familial benign chronic pemphigus in a patient undergoing treatment with efalizumab for psoriasis. J Eur Acad Dermatol Venereol : JEADV 23:605-606

111. Adnot-Desanlis L, Antonicelli F, Tabary T, Bernard P, Reguiai Z (2013) Effectiveness of infliximab in pityriasis rubra pilaris is associated with pro-inflammatory cytokine inhibition. Dermatology (Basel, Switzerland) 226:41-46

112. Wohlrab J, Kreft B (2010) Treatment of pityriasis rubra pilaris with ustekinumab. Br J Dermatol 163:655-656

113. Klein A, Szeimies RM, Landthaler M, Karrer S (2007) Exacerbation of pityriasis rubra pilaris under efalizumab therapy. Dermatology (Basel, Switzerland) 215:72-75

114. Gomez M, Ruelas ME, Welsh O, Arcaute HD, Ocampo-Candiani J (2007) Clinical improvement of pityriasis rubra pilaris with 
efalizumab in a pediatric patient. J Drugs Dermatol : JDD 6:337339

115. Shima Y, Kuwahara Y, Murota H et al (2010) The skin of patients with systemic sclerosis softened during the treatment with anti-IL6 receptor antibody tocilizumab. Rheumatology (Oxford) 49: 2408-2412

116. Elhai M, Meunier M, Matucci-Cerinic M et al (2013) Outcomes of patients with systemic sclerosis-associated polyarthritis and myopathy treated with tocilizumab or abatacept: a EUSTAR observational study. Ann Rheum Dis 72:1217-1220

117. Phumethum V, Jamal S, Johnson SR (2011) Biologic therapy for systemic sclerosis: a systematic review. J Rheumatol 38:289-296

118. Jordan S, Distler JH, Maurer B et al (2015) Effects and safety of rituximab in systemic sclerosis: an analysis from the European Scleroderma Trial and Research (EUSTAR) group. Ann Rheum Dis 74:1188-1194

119. Chi GC, Hsu FS, Yang CC, Wei JC (2005) Scleroderma and failed response to alefacept. Rheumatology (Oxford) 44:1328-1330

120. Gonzalez-Lopez MA, Martinez-Taboada VM, Gonzalez-Vela MC, Fernandez-Llaca H, Val-Bernal JF (2008) New-onset psoriasis following treatment with the interleukin-1 receptor antagonist anakinra. Br J Dermatol 158:1146-1148

121. Palmou-Fontana N, Sanchez Gavino JA, McGonagle D, GarciaMartinez E, Iniguezde Onzono Martin L (2014) Tocilizumabinduced psoriasiform rash in rheumatoid arthritis. Dermatology (Basel, Switzerland) 228:311-313

122. Reich K, Nestle FO, Papp K et al (2005) Infliximab induction and maintenance therapy for moderate-to-severe psoriasis: a phase III, multicentre, double-blind trial. Lancet (London, England) 366: 1367-1374

123. Papp KA, Langley RG, Lebwohl M et al (2008) Efficacy and safety of ustekinumab, a human interleukin-12/23 monoclonal antibody, in patients with psoriasis: 52-week results from a randomised, double-blind, placebo-controlled trial (PHOENIX 2). Lancet (London, England) 371:1675-1684

124. Langley RG, Elewski BE, Lebwohl M et al (2014) Secukinumab in plaque psoriasis - results of two phase 3 trials. N Engl J Med 371:326-338

125. Toussirot E (2013) New onset of psoriasis in a patient with rheumatoid arthritis treated with rituximab. J Rheumatol 40:1230-1231

126. Pariser DM, Gordon KB, Papp KA et al (2005) Clinical efficacy of efalizumab in patients with chronic plaque psoriasis: results from three randomized placebo-controlled phase III trials: part I. J Cutan Med Surg 9:303-312

127. Ellis CN, Krueger GG (2001) Treatment of chronic plaque psoriasis by selective targeting of memory effector T lymphocytes. N Engl J Med 345:248-255

128. Brenner M, Ruzicka T, Plewig G, Thomas P, Herzer P (2009) Targeted treatment of pyoderma gangrenosum in PAPA (pyogenic arthritis, pyoderma gangrenosum and acne) syndrome with the recombinant human interleukin-1 receptor antagonist anakinra. Br J Dermatol 161:1199-1201

129. Acquitter M, Plantin P, Kupfer I, Auvinet H, Marhadour T (2015) Anakinra improves pyoderma gangrenosum in psoriatic arthritis: a case report. Ann Intern Med 163:70-71

130. Brooklyn TN, Dunnill MG, Shetty A et al (2006) Infliximab for the treatment of pyoderma gangrenosum: a randomised, double blind, placebo controlled trial. Gut 55:505-509

131. Guenova E, Teske A, Fehrenbacher B et al (2011) Interleukin 23 expression in pyoderma gangrenosum and targeted therapy with ustekinumab. Arch Dermatol 147:1203-1205

132. Kleinpenning MM, Langewouters AM, Van De Kerkhof PC, Greebe RJ (2011) Severe pyoderma gangrenosum unresponsive to etanercept and adalimumab. J Dermatolog Treat 22:261-265

133. Selva-Nayagam P, Fischer G, Hamann I, Sobel J, James C (2015) Rituximab causing deep ulcerative suppurative vaginitis/ pyoderma gangrenosum. Curr Infect Dis Rep 17:478

134. Foss CE, Clark AR, Inabinet R, Camacho F, Jorizzo JL (2008) An open-label pilot study of alefacept for the treatment of pyoderma gangrenosum. J Eur Acad Dermatol Venereol : JEADV 22:943949

135. Nutz A, Pernet C, Combe B, Cohen JD (2013) Sarcoidosis induced by tocilizumab: a paradoxical event? J Rheumatol 40: 1773-1774

136. Rossman MD, Newman LS, Baughman RP et al (2006) A doubleblinded, randomized, placebo-controlled trial of infliximab in subjects with active pulmonary sarcoidosis. Sarcoidosis Vasc Diffuse Lung Dis 23:201-208

137. Kaiser CA, Cozzio A, Hofbauer GF, Kamarashev J, French LE, Navarini AA (2011) Disfiguring annular sarcoidosis improved by adalimumab. Case Rep Dermatology 3:103-106

138. Judson MA, Baughman RP, Costabel U et al (2014) Safety and efficacy of ustekinumab or golimumab in patients with chronic sarcoidosis. Eur Respir J 44:1296-1307

139. Sweiss NJ, Lower EE, Mirsaeidi M et al (2014) Rituximab in the treatment of refractory pulmonary sarcoidosis. Eur Respir J 43: $1525-1528$

140. Garcia-Zuazaga J, Korman NJ (2006) Cutaneous sarcoidosis successfully treated with alefacept. J Cutan Med Surg 10:300-303

141. Devauchelle-Pensec V, Mariette X, Jousse-Joulin S et al (2014) Treatment of primary Sjogren syndrome with rituximab: a randomized trial. Ann Intern Med 160:233-242

142. Moutsopoulos NM, Katsifis GE, Angelov N et al (2008) Lack of efficacy of etanercept in Sjogren syndrome correlates with failed suppression of tumour necrosis factor alpha and systemic immune activation. Ann Rheum Dis 67:1437-1443

143. Voigtlander C, Luftl M, Schuler G, Hertl M (2001) Infliximab (anti-tumor necrosis factor alpha antibody): a novel, highly effective treatment of recalcitrant subcorneal pustular dermatosis (Sneddon-Wilkinson disease). Arch Dermatol 137:1571-1574

144. Sauder MB, Glassman SJ (2013) Palmoplantar subcorneal pustular dermatosis following adalimumab therapy for rheumatoid arthritis. Int J Dermatol 52:624-628

145. Kluger N, Gil-Bistes D, Guillot B, Bessis D (2011) Efficacy of anti-interleukin-1 receptor antagonist anakinra $(\operatorname{Kineret}(\mathrm{R}))$ in a case of refractory Sweet's syndrome. Dermatology (Basel, Switzerland) 222:123-127

146. Foster EN, Nguyen KK, Sheikh RA, Prindiville TP (2005) Crohn's disease associated with Sweet's syndrome and Sjogren's syndrome treated with infliximab. Clin Dev Immunol 12:145-149

147. Zarate-Correa LC, Carrillo-Gomez DC, Ramirez-Escobar AF, Serrano-Reyes C (2013) Toxic epidermal necrolysis successfully treated with infliximab. J Investig Allergol Clin Immunol 23:61-63

148. Lowndes S, Darby A, Mead G, Lister A (2002) Stevens-Johnson syndrome after treatment with rituximab. Ann Oncol 13:1948-1950

149. (2005) Etanercept plus standard therapy for Wegener's granulomatosis. N Engl J Med 352:351-61

150. Miloslavsky EM, Specks U, Merkel PA et al (2013) Clinical outcomes of remission induction therapy for severe antineutrophil cytoplasmic antibody-associated vasculitis. Arthritis Rheum 65: 2441-2449 